\title{
ASISTENSI MENGAJAR, ADAPTASI TEKNOLOGI, DAN ADMINISTRASI DALAM PROGRAM KAMPUS MENGAJAR
}

\author{
${ }^{1 *}$ Heri Dwi Santoso, ${ }^{2}$ Diana Puspita Sari, ${ }^{3}$ Apriliana Dian Fadilla, \\ ${ }^{4}$ Faidah Fitri Utami, ${ }^{5}$ Fitria Pangesti Rahayu, ${ }^{6}$ Della Chamelia Sari, \\ ${ }^{7}$ Niken Putri Sya'bani \\ ${ }^{1}$ Universitas Muhammadiyah Semarang, Kota Semarang, Indonesia \\ ${ }^{2,3}$ Universitas Muhammadiyah Purworejo, Purworejo, Indonesia \\ ${ }^{4,7}$ Universitas Jenderal Soedirman, Purwokerto, Indonesia \\ ${ }^{5}$ Universitas Siliwangi, Tasikmalaya, Indonesia \\ ${ }^{6}$ Universitas Sarjanawiyata Tamansiswa, Kota Yogyakarta, Indonesia \\ Email : " heridwi.santoso@unimus.ac.id
}

Manuskrip: September -2021; Ditinjau: September -2021; Diterima: Oktober -2021;

Online: Januari-2022; Diterbitkan: Januari-2022

\begin{abstract}
ABSTRAK
Kampus Mengajar dibuka sebagai program yang memberikan kesempatan kepada mahasiswa untuk mendapatkan pengalaman belajar di luar kampus dengan konversi 20 SKS. Program ini bertujuan untuk memfasilitasi mahasiswa untuk berkontribusi di dalam pendidikan di tingkat sekolah dasar dan sekolah menengah pertama, di bawah bimbingan dosen pembimbing lapangan. Metode pelaksanaan program ini antara lain meliputi asistensi mengajar, adaptasi teknologi, dan administrasi bagi guru dan siswa sekolah yang bersangkutan. Kampus mengajar Angkatan 2 di SD Negeri 1 Pandak, Kecamatan Baturraden, Kabupaten Banyumas, Provinsi Jawa Tengah dilaksanakan oleh enam mahasiswa dari perguruan tinggi yang berbeda dengan 1 dosen pembimbing. Hasil dari program ini meliputi peningkatan pelayanan pendidikan di sekolah tersebut baik dari segi pengajaran, pemanfaatan teknologi, dan administrasi. Dapat disimpulkan bahwa program Kampus mengajar ini memberikan manfaat yang baik bagi semua pihak yang terlibat, baik sekolah, mahasiswa, maupun dosen pembimbing.
\end{abstract}

\section{Kata Kunci: Kampus Mengajar, Sekolah Dasar, Asistensi Mengajar, Adaptasi Teknologi, Administrasi Sekolah}

\section{PENDAHULUAN}

Sejak Merdeka Belajar Kampus Merdeka (MBKM) dicanangkan, berbagai program pembelajaran luar kelas ditawarkan dan dapat diakses mahasiswa di segala penjuru nusantara. Ada 8 (delapan) Bidang Kegiatan Pembelajaran (BKP) yang termasuk dalam MBKM yaitu a) pertukaran pelajar, b) magang/praktik kerja, c) asistensi mengajar di satuan pendidikan, d) penelitian/riset, e) proyek kemanusiaan, f) kegiatan wirausaha, g) studi/proyek independent, dan h) membangun desa/kuliah kerja nyata tematik (Direktorat Jenderal Pendidikan Tinggi, 2020; Siregar et al., 
2020). Selaras dengan sistem baru yang dicanangkan Nadiem Makarim ini, pemerintah membuka program-program yang mencakup delapan BKP di atas yang difasilitasi melalui laman kampusmerdeka.kemdikbud.go.id. Salah satunya yang mulai marak diikuti mahasiswa saat ini adalah program Kampus Mengajar yang masuk dalam BKP Asistensi Mengajar di Satuan Pendidikan.

Program Kampus mengajar adalah program satu semester yang telah dimulai pada tahun 2020, dengan Kampus Mengajar Perintis, kemudian dilanjutkan dengan Kampus Mengajar Angkatan 1 dan Kampus Mengajar Angkatan 2 pada tahun 2021. Program ini dibuka dengan tujuan untuk memberikan kesempatan mahasiswa belajar dan mengembangkan diri di luar kampus melalui asistensi mengajar di satuan Pendidikan(Mengajar et al., 2021; Muhamad \& Anugrah, 2021).

Meskipun begitu, pada praktiknya, tugas mahasiswa di program Kampus Mengajar tidak hanya mengajar. Tugas inti dari mahasiswa peserta Kampus Mengajar meliputi a) membantu mengajar numerasi, b) membantu mengajar literasi, c) membantu adaptasi teknologi, dan membantu administrasi (Sub Pokja Kampus Mengajar, 2021). Keempat jenis tugas tersebut tentu saja kompleks namun akan mengasah softskill mahasiswa baik dalam hal kepemimpinan, kerjasama, empati, kreativitas, dan lain sebagainya yang akan berguna kelak setelah lulus. Tugas-tugas tersebut juga selaras dengan slogan Kampus Mengajar yaitu "Mengabdi untuk Negeri”, melalui pengabdian dalam bidang pendidikan di tingkat sekolah dasar dan sekolah menengah pertama.

Sebagai bentuk pengabdian kepada masyarakat, kegiatan-kegiatan yang dilakukan di sekolah mitra tentunya harus memberikan dampak nyata bagi pengembangan dan/atau perbaikan kualitas sekolah. Oleh karena itu, sekolahsekolah, baik SD maupun SMP yang ditunjuk sebagai mitra memiliki kriteria tertentu, yaitu maksimal terakreditasi B (Anwar, 2021). Hal ini dengan asumsi bahwa sekolah-sekolah tersebut masih memerlukan peningkatan-peningkatan kualitas yang harapannya dapat dibantu dengan adanya program Kampus Mengajar.

Tabel 1. Jumlah Siswa di SD Negeri 1 Pandak

\begin{tabular}{|c|l|c|}
\hline No. & Kelas & Jumlah Siswa (Orang) \\
\hline 1 & Kelas I & 8 \\
\hline 2 & Kelas II & 11 \\
\hline 3 & Kelas III & 13 \\
\hline 4 & Kelas IV & 13 \\
\hline 5 & Kelas V & 10 \\
\hline 6 & Kelas VI & 7 \\
\hline
\end{tabular}

Salah satu mitra dalam program Kampus Mengajar adalah SD Negeri 1 Pandak di Kecamatan Baturraden, Kabupaten Banyumas, Provinsi Jawa Tengah. Pelaksanaan program Kampus Mengajar di sekolah tersebut adalah pada program Kampus Mengajar Angkatan 3 Tahun 2021. Ada beberapa hal yang ditemukan di SD Negeri 1 Pandak yang perlu mendapat perhatian, yang juga merupakan kekurangan dari sekolah tersebut diantaranya adalah jumlah peserta didik yang masih sedikit, sarana dan prasarana sekolah yang belum sesuai standar, serta jumlah tenaga pengajar yang masih kurang 


\section{METODE}

Kegiatan Kampus Mengajar Angkatan 3 di SD Neger I 1 Pandak, Kecamatan Baturraden, Kabupaten Banyumas dilaksanakan oleh 6 (enam) mahasiswa dan 1 (satu) Dosen Pembimbing Lapangan (DPL) yang berasal dari 5 (lima) perguruan tinggi. Metode pengabdian merujuk pada ketentuan tugas mahasiswa yaitu a) membantu mengajar numerasi, b) membantu mengajar literasi, c) membantu adaptasi teknologi, dan d) membantu administrasi. Langkah-langkah kegiatan meliputi tahap persiapan, tahap pelaksanaan, dan tahap pelaporan, yang dilaksanakan dalam kurun waktu 6 (enam) bulan atau 1 (satu) semester penuh dari bulan Agustus sampai dengan bulan Desember 2021.

Adapun setiap tahap kegiatan dilaksanakan sesuai prosedur yang selama ini berlaku di Kampus Merdeka (Nurhasanah \& Nopianti, 2021), sebagaimana diuraikan pada bagan berikut ini:

\begin{tabular}{|c|c|c|}
\hline \begin{tabular}{l}
$\quad$ TAHAP \\
\multicolumn{1}{c}{ PERSIAPAN } \\
- Observasi \\
- Identifikasi Masalah \\
- Laporan Awal
\end{tabular} & \begin{tabular}{l}
\multicolumn{1}{c}{ TAHAP } \\
PELAKSANAAN \\
- Laporan Harian \\
(Logbook) \\
- Laporan Mingguan
\end{tabular} & $\begin{array}{c}\text { TAHAP ANALISIS } \\
\text { HASIL } \\
\text { Laporan Akhir }\end{array}$ \\
\hline
\end{tabular}

Bagan 1. Alur Pelaksanaan Program Kampus Mengajar

Tahap pertama, persiapan, diisi dengan kegiatan observasi ke sekolah prapenugasan dengan tujuan untuk mengetahui situasi dan kondisi di sekolah. Dari observasi dilakukan identifikasi masalah secara bersama-sama oleh tim Kampus Mengajar untuk selanjutnya dilaporkan dalam bentuk laporan awal. Laporan awal disampaikan pada minggu pertama penugasan.

Tahap kedua adalah pelaksanaan. Pada tahap ini tim Kampus Mengajar melaksanakan program selama 20 (dua puluh minggu) mulai bulan Agustus 2021 sampai dengan Desember 2021. Pada tahap ini mahasiswa melakukan koordinasi secara berkelanjutan dengan DPL, membuat laporan harian dalam logbook untuk divalidasi DPL, serta membuat laporan mingguan. Adapun, sharing session dilakukan dua minggu sekali di sepanjang program.

Tahap terakhir yaitu tahap analisis hasil pengabdian Kampus Mengajar yang disampaikan dalam bentuk laporan akhir. Laporan akhir ini disusun setelah kegiatan pelaksanaan program selama dua puluh minggu selesai dilakukan. Pada tahap ini, kinerja dari masing-masing mahasiswa dinilai oleh DPL, sejawat, dan guru pamong

\section{HASIL DAN PEMBAHASAN}

Program Kampus Mengajar Angkatan 2 di SD Negeri 1 Pandak, Kecamatan Baturraden, Kabupaten Banyumas, Jawa Tengah yang terlaksana mencakup beberapa aspek kegiatan antara lain:

\section{A. Aspek Pengajaran}

1. Mengajar Keliling

Kegiatan ini merupakan kegiatan belajar mengajar yang dilaksanakan ke rumah-rumah siswa dilakukan secara berkelompok dimana kegiatan ini 
berorientasi untuk membantu guru dalam mengajar. Mekanisme kegiatan ini mahasiswa datang ke rumah siswa secara berkelompok dan membantu guru dalam proses belajar mengajar. Kegiatan ini dilakukan secara luring rumah ke rumah dengan tetap menerapkan protokol kesehatan.

2. Fun Experiment

Kegiatan ini merupakan suatu eksperimen dari materi yang telah dipelajari agar siswa dapat mengaplikasi kan secara nyata dari pembelajaran yang telah didapat. Mekanisme kegiatan ini mahasiswa datang ke rumah siswa secara berkelompok dan membuat eksperimen dari materi yang telah dipelajari.

3. Gemar literasi

Kegiatan ini dilakukan untuk meningkatkan literasi siswa, yang mana siswa akan diminta untuk menarik kesimpulan atau menceritakan kembali tentang buku yang telah dibacanya. Mekanisme dalam kegiatan ini, siswa diminta untuk membaca terlebih dahulu tentang buku-buku yang disediakan, seperti buku dongeng ataupun buku cerita lainnya, lalu siswa diminta untuk menarik kesimpulan atau menceritakan kembali tentang buku yang telah dibacanya.

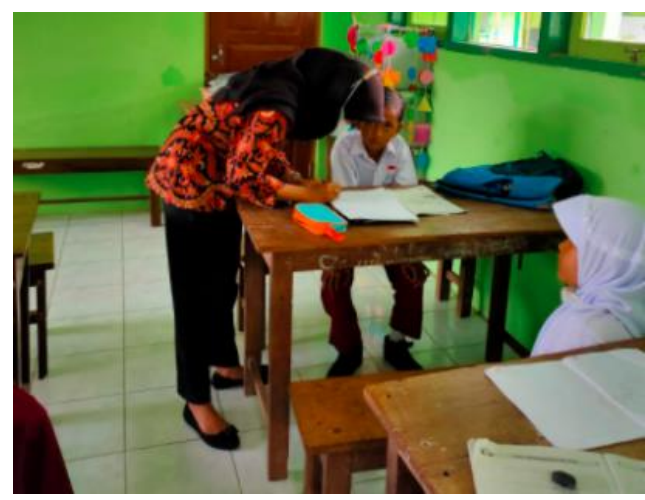

Gambar 1. Drilling Literasi Siswa dengan Membaca Cerita

\section{English Fun}

Kegiatan ini mengajarkan bahasa inggris dasar seperti, huruf, angka, warna, dll. Mekanisme kegiatan ini dengan cara mengajarkan bahasa inggris dasar kepada siswa memperkenalkan diri menggunakan bahasa Inggris, dengan target yaitu pemahaman siswa pada setiap sesi pembelajaran.

\section{B. Adaptasi Teknologi}

1. Penggunaan teknologi digital dalam pembelajaran daring

Kegiatan ini merupakan bentuk kegiatan belajar mengajar secara daring yang dengna berbagai platform seperti Google meet, Google Classroom, dan e-learning lainnya yang membantu memudahkan guru dan siswa pada saat belajar mengajar secara daring. Mekanisme kegiatan ini dilakukan secara daring untuk mengumpulkan tugas atau mengirim materi pembelajaran. 


\section{Game Edukasi Digital}

Kegiatan ini merupakan bentuk kegiatan belajar mengajar dalam bentuk game secara daring yang dapat dilakukan misalnya dengan quiziz, kahoot, AKSI, dll. Mekanisme kegiatan ini dilakukan secara daring untuk menjawab soal seusai pembelajaran sebagai mini evaluasi, atau untuk mengerjakan soal secara sederhana.

\section{Administrasi}

1. Penataan kelas, UKS, dan Perpustakaan.

Kegiatan in merupakan penataan dan membersihkan ruang kelas, UKS, dan perpustakaan yang kondisinya masih belum tertata rapi karena masa pandemi sehingga ruangan-ruangan tersebut lama tidak digunakan.

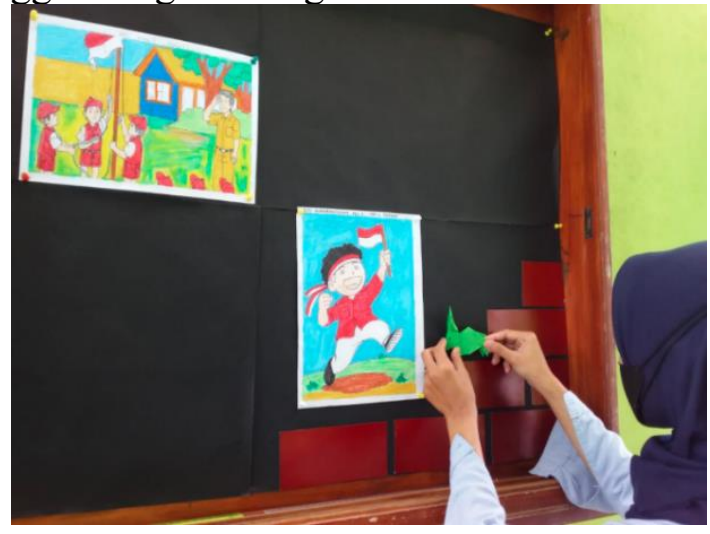

Gambar 2. Penataan Majalah Dinding Sekolah

Mekanisme kegiatan penataan kelas dan UKS, dilakukan pembersihan, dan penataan agar menjadi lebih rapi. Sementara untuk penataan perpustakaan dilakukan dengan memberikan penomoran pada buku-buku baru dan pembersihan ruangan perpustakaan agar terlihat lebih rapid dan bersih.

2. Membantu mengoreksi dan remedial siswa

Kegiatan ini merupakan kegiatan mahasiswa membantu guru untuk menilai tugas siswa yang telah dikumpulkan. Mekanisme kegiatan ini dilakukan setelah siswa mengumpulkan tugas-tugasnya, lalu mahasiswa membantu guru untuk mengoreksi dan apabila terdapat siswa dengan nilai kurang maka diadakan remedial untuk membantu guru dan agar siswa menjadi lebih paham akan materinya.

\section{KESIMPULAN}

Program Kampus Mengajar Angkatan 2 dengan mitra SD Negeri 1 Pandak, Kecamatan Baturraden, Kabupaten Banyumas, Provinsi Jawa Tengah telah memberikan dampak yang positif bagi penyelenggaraan Pendidikan di sekolah tersebut. Tim Kampus Mengajar telah berkontribusi dalam peningkatan kualitas layanan Pendidikan baik dalam hal pengajaran, pemanfaatan teknologi dan 
informasi, serta pembenahan administrasi yang ada di sekolah tersebut. Selama kurun waktu dua puluh minggu atau kurang lebih 1 semester, mahasiswa dan DPL telah bersinergi dalam melaksanakan program berdasarkan program kerja yang dibuat di awal program, yang merujuk pada hasil observasi dan analisis situasi di lapangan.

\section{UCAPAN TERIMA KASIH}

Ucapan terima kasih pengabdi haturkan kepada Kementerian Pendidikan, Kebudayaan, Riset, dan Teknologi yang memfasilitasi pembelajaran di luar kampus melalui program Kampus Mengajar Angkatan 2 ini. Terima kasih juga disampaikan kepada segenap kepala sekolah, guru, serta segenap staf di SD Negeri 1 Pandak yang telah menerima dengan baik, memfasilitasi, serta bekerjasama dengan tim dalam program Kampus Mengajar Angkatan 2 ini

\section{DAFTAR PUSTAKA}

Anwar, R. N. (2021). Pelaksanaan Kampus Mengajar Angkatan 1 Program Merdeka Belajar Kampus Merdeka di Sekolah Dasar. Jurnal Pendidikan Dan Kewirausahaan, 9(1), 210-220. https://doi.org/10.47668/PKWU.V9I1.221

Direktorat Jenderal Pendidikan Tinggi. (2020). Buku Panduan Merdeka Belajar Kampus Merdeka. Direktorat Jenderal Pendidikan Tinggi Kemdikbud RI.

Mengajar, K., Transformasi, :, Belajar, B., Dalam, S., Kebiasaan, A., Di, B., Athi', M., Rahmah, N. A., \& Triristina, N. (2021). Kampus Mengajar: Transformasi Budaya Belajar Siswa Dalam Adaptasi Kebiasaan Baru Di Madura. NiCMa: National Conference Multidisplinary, $\quad 1(1), \quad 34-39$. https://doi.org/10.32492/NICMA.V1I1.313

Muhamad, T., \& Anugrah, F. (2021). Implementasi Pelaksanaan Program Kampus Mengajar Angkatan 1 Terdampak Pandemi Covid-19. Akselerasi: Jurnal Ilmiah Nasional, 3(3), 38-47. https://doi.org/10.54783/JIN.V3I3.458

Dewi, R. V. K., Sunarsi, D., \& Akbar, I. R. (2020). Dampak Penggunaan Teknologi Informasi dan Komunikasi Terhadap Minat Belajar Siswa di SMK Ganesa Satria Depok. Jurnal Ilmiah Wahana Pendidikan, 6(4), 1001-1007.

Nurhasanah, A. D., \& Nopianti, H. (2021). Peran Mahasiswa Program Kampus Mengajar Dalam Meningkatkan Kompetensi SDN 48 Bengkulu Tengah. SNPKM: Seminar Nasional Pengabdian Kepada Masyarakat, 3, 166-173. http://journal.unilak.ac.id/index.php/SNPKM/article/view/8066

Siregar, N., Sahirah, R., \& Harahap, A. A. (2020). Konsep Kampus Merdeka Belajar di Era Revolusi Industri 4.0. Fitrah: Journal of Islamic Education, 1(1), 141157. https://doi.org/10.53802/FITRAH.V1I1.13

Sub Pokja Kampus Mengajar. (2021). Panduan Pendaftaran Kampus Mengajar Angkatan 2 Tahun 2021. Direktorat Jenderal Pendidikan Tinggi Kemdikbud RI. 